\section{Qlinital Alecture}

on

\section{A C U T E H E P T I T I S.}

DELIVERED AT

ST. MARY'S HOSPITAL, FEB. 23RD, 1861.

BY

THOMAS K. CHAMBERS, M.D.,

FELLOW AND GENSOR OF THE ROYAL COLLEGE OF PHYSICIANS OF LONDON; PHYSICIAN TO ST. MARY'S HOSPITAL; ETC.

Aworg the patients admitted yesterday, is an instance of a disease by no means common in this country-acute inflammation of the liver.

Sarah D., aged 45 , was brought to the Hospital by a lady in whose service she has been living as cook. She states that she has usually been a healthy woman, has worked hard, and seldom been incapacitated. She has taken "her beer" with extreme regularity, to keep her strength up, and has occasionally indulged herself in a little spirits. The catamenia are regular. She has been ailing, with what she calls "a cold", for three weeks, and has lost her voice for a fortnight; but has had no acute or prominent symptoms till nine days ago, when she was attacked at night with severe shiverings and pains in the back and round the waist. She entirely lost her appetite, and had much thirst. She frequently vomited, throwing up her food. The pain in the waist got fixed in the epigastrium, is described as of a dull heavy character, running round to the right hypochon drium, and much increased by drawing the breath. The rigors have frequently returned from time to time, but the thirst has somewhat abated. The bowels, which have always been costive, have become more so than usual; and the motions, when elicited by medicines, are quite pale. The urine is thick and high coloured. The skin is altered in colour, being of a pale yellow tirit for the last few days, but not absolutely jaundiced. On examination, there is considerable pain on pressure in the epigastrium, in the right hypochondrium, and beneath the right scapula. The epigastrium is dull on percussion, and the extent of dulness in the right infrascapular region measures perpendicularly about four inches. The respiration in the lower lobe of the right lung is natural. The pulse is 80 , full and hard. The tongue has a moderately thick white fur.

I will tell you why I have made the diagnosis of inflammation of the liver in this case, and how, par la voie d'exclusion, I have argued to myself that such a really rare state of things exists. In the first place, I said to myself, the general symptoms show there is acute inflammation somewhere: there are rigors, thirst, loss of appetite, a quick, full, and hard pulse, a furred tongue, without the dry hot skin, the depression, or the hurried circulation of low fever. This inflammation is not in a serous membrane; the pulse is not quick and hard enough; there is no very sharp or stabbing pain in any of those parts which I know to be lined with serous membrane.

Looking over, then, the parenchymatous structures in which the inflammation is likely to be situated, I am happy to find, by the assistance of the stethoscope, it is not in the lungs. And then I find that there is a dull heavy pain in the space occupied by the liver; and that in the part of this viscus which comes nearest to the surface, namely, the front edge of the left lobe, I produce severe pain by pressure. The same pain is also produced by firm pressure in the right hypochondrium and in the back. I find also a moderate enlargement of the organ, indicated by dulness on percussion rather more extensive than ordinary. I also find vomiting, arising, I conceive, from irritation of the stomach by the special affection of the left lobe, which overlies that part of the digestive canal. Bile is deficient in the stools; but its constituents are present in the urine, which deposits lithate of soda and purpurates in abundance.

These latter symptoms might, it is true, be equally well produced by obstruction of the gall-ducts; but then, you remark, they are in this patient preceded by rigors, thirst, fever, and other signs of acute inflammation, which would not be the case in obstructed gall-ducts.

The skin, again, is of a peculiar tint, not green or bright yellow, but of a peculiar faded leaf colour, which is often observed in India as a concomitant of hepatitis. It is very similar to what is seen often in gastric and bilious fevers; but very different from true icterus.

Add to this the woman's occupation. She is a hardworking cook, baking and congesting her liver all day long in a hot kitchen, just as our zealous countrymen are doing in the kitchen-like climates of the tropics. She has thought it incumbent upon her to take that almost hourly allowance of glutinous fermented liquids which servants call "their beer", and has moreover kept off the natural depression of reaction by occasional doses of spirits. Most likely she has never got drunk in her life-so much the worse; it is not the intoxicating excess, necessarily exceptional, and which works its own cure by reaction, that produces disease; but the constant petty tippling. By this, a permanent state of arrest in the vital functions is induced ; metamorphosis and the renewal of the tissues are checked; and what else can be the result but a gradually increasing degeneration of the glandular structures? Foremost among the viscera exposed to the gradual poison of the alcohol stands the liver, so near to the thin walls of the stomach, and the recipient of all the spirit-loaded blood of the digestive canal; and, consequently, we find it choked up with effete degenerating cells. It is most probably so affected chronically in this woman, just as it is in most old Indians. Her hard work and her hot kitchen have done the rest; and have produced, as I believe, acute parenchymatous inflammation in various parts of the structure.

I say "in various parts of the structure", because inflammation of the liver never, so far as I know, has been found attacking the whole organ. It occurs in one or more circumscribed patches, generally only in one patch. Patients scarcely ever die during the hyperæmic stage ; but if they should do so, you would find (in the words of Professor Rokitansky) "the parenchyma loosened and lacerable, and the structure more apparent from the enlargement of the acini, which gives the broken surface a granular appearance; the acini become altered in shape, and assume an oval form....... In a more advanced stage, the granulated structure disappears, the tissue seems perfectly uniform, and the broken surface has a laminated appearance." What the appearances are when it has run on to suppuration, you have all 
had recently exhibited to you in the mortuary in an enormous abscess, which is excellently described by Dr. Broadbent, in the Post Mortem Book, vol. vi. But I need not detail to you what an abscess is; the point I have to notice is that it occupies a circumscribed spot or spots in the liver, and that the greater part of the structure remains healthy.

We have in the case of Sarah D. nearly all the symptoms by which hepatitis is ever indicated; for "pain in the right shoulder", which you often see included among them, is, when present, really only accidental-it arises from derangement of the stomach or duodenum or colon, and not of the liver. Never more, and usually much less, evidence of the lesion we are considering is to be found. Even when the inflammation runs on to abscess, it is singular how little the attention is drawn to the seat of injury by pain. Most of you saw a woman that I admitted in Dr. Sibson's week, during his holiday last autumn. It is true, I did make the diagnosis of abscess of the liver, and treated it as such, guided in a great degree by the same peculiar faded leaf colour of the skin, which there is in this case, and by her having had abscesses in the groins ; but I felt very dubious about it, till, some time after she had passed from my care, the abscess burst through the lungs, and several pints of pus were thrown up. Quite recently, after her death by exhaustion, you saw that this abscess, so difficult to discover, was nearly as big as a man's head. Sometimes the existence of such a thing is never even guessed before death. A young woman in Victoria ward, a patient of mine, convalescent from low fever, died suddenly from syncope, consequent on rising suddenly from her bed. The post mortem examination revealed the existence of a hepatic abscess as big as an orange, which had produced no symptoms at all. In other cases, again, nothing is known about the abscess till it forms adhesions with the abdominal walls, and points externally.

What I have been lecturing about is that which a pathologist and a physician would call inflammation of the liver. An essential part of it is the true inflammatory state which I have described, and it is happily a rare disease. But patients will come almost daily, telling you that they are subject to or at least have had "inflammation of the liver"; where, on inquiry, you find no evidence at all of inflammatory fever. If there be any hepatic disease at all, it is generally slight cirrhosis ; but nine times out of ten they have had hepatalgia or pain in the superficial nerves of the liver, and pain in the right shoulder, arising from derangement of duodenum, colon, or stomach. If you treat this as hepatitis, you will convert the case in the end into chronic dyspepsia.

True hepatitis in a large proportion of cases runs on to suppuration; but sometimes it is resolved by treatment. The indications of resolution are the subsidence of the fever, the gastric symptoms, and the pain. Then the swelling subsides, and the epigastrium and right hypochondrium lose their tension and fulness. I hope that such a result may follow in this instance; but it is an early day to give a favourable prognosis. The treatment I have put her upon consists of repeated small doses of mercurials, which I shall push to the extent of affecting the system, purgatives, and leeches to the hepatic region, followed by the continuous application of a linseed poultice; I shall repeat the leeches frequently. Venesection, which is of so much value in another parenchymatous inflammation, pneumonia, is not, I think, so strongly indicated here. Its chief influence is on the heart, and through that organ on the pulmonary circulation. But in hepatitis the sanguineous circulation which you would chiefly desire to intuence is the portal and peritoneal, and the nearest point to get at that is on the abdominal parietes. I confess to you I do not know how it is that leeches applied to the outside of the belly relieve the congestion and inflammation of the dependencies of the portal system ; and I am equally ignorant how cupping the surface of the chest relieves the lung; but that they both do so, in spite of the little connexion between the places to be found in anatomical geography, I am sure. Just as I put on leeches to the right iliac fossa to relieve the inflammation of the bowels in zymotic fever, so I put them to the hypochondrium and epigastrium here in hopes to relieve the liver.

I have been careful here to sketch only the outlines of the treatment, that I may not confuse you by placing too much in the foreground accidental variations in complicated cases. The essentials are local blood-letting, poultices, and mercury.

Supposing this plan to be successful, you will, of course, not see the result; and you may be curious to know what traces of the battle remain. I believe we see those traces in the shape of scars in the livers of persons who have died of some other disease. In scattered spots you find the parenchyma obliterated and converted into a lump of yellowish white fibrine, contracted and furrowed, and dragging in the surface of the viscus, just like a contracting scar in any other part. The neighbouring structure is usually in a perfectly efficient state. These I believe to be the result of slight or cured inflammatory attacks.

[This patient got well by a continuous improvement, and was able to return to her place.-T. K. C.]

The Seal and the Esquinaux. The seal is a very wary animal, with acute sight, smeli, and hearing; but it is no match for the Eskimo hunter, who, sheltered from the keen blast by a semi-circular wall of snow, will sit motionless for hours, watching for the bubble of air that warns him of the seal coming up to breathe. And scarcely has the animal raised its nostrils to the surface, before the hunter's harpoon is deeply buried in its body. This sport is not without the danger that adds to the excitement of success. The line attached to the point of the harpoon is passed in a loop round the hunter's loins; and should the animal he has struck be a large seal or walrus, woe betide him if he does not instantly plant his feet in the notch cut for the purpose in the ice, and throw himself in such a position that the strain on the line is as nearly as possible brought into the direction of the length of the spine of his back and axis of his lower limbs. A transverse pull from one of these powerful beasts would double him up across the airhole, and perhaps break his back; or if the opening be large, as it often is when the spring is advanced, he would be dragged under water and drowned. Accidents of this kind are but too common. When the seals come out on the ice to bask in the powerful rays of a spring sun, the Eskimo hunter knows how to approach them by imitating their forms and motions so perfectly that the poor animals take him for one of their own species, and are not undeceived until he comes near enough to thrust his lance into one. (Sir J. Richardson.) 